\title{
An Open Source Social App for Events Management in Oman
}

\author{
Fatma Salim Ali AL.Farsi ${ }^{\mathrm{a}}$
}

The main aim of the research is to study the advancement and ethical feasibility in the field of event management and to Design and develop an application for Oman Events. The application will be developed using open source software and will be available to the aspires in free of cost to promote more events in Oman. DSDM methodology is adopted to develop the application. This application will give full information about events. Ministry of Information to analyze the requirements of the project. To improve the usability of the application, GPS will be added for finding the location of events. The application will increase the social awareness among the Omanis in addition to promoting more events in Oman and hence the economy.

Keywords: Ethical Feasibility, DSDM, Performance.

\section{Introduction}

Events have a big role in a lot of institutions, but most people do not know of these events, and their significance, so the research will highlight the importance of these events. And also some people have difficulty knowing where the timing of events held in their city. That is a problem faced by people who want to attend the event and the person who wants to present at the event. The persons who are not able to attend the events may not know about the place, time or aim of the event but with this application this will be easy for them. Also the person who wants to conduct an event will face some problems like there may not be a large number of attendees or because of lack of information.

\section{MINISTRY OF INFORMATION WEBSITE}

The Ministry of information has a special website and the website includes its vision and mission, strategic objectives, media laws, media services, updates, tenders, publications and a photo gallery. This website offers everything related to the media. But there is not more focus on the activities and events that are held in the Sultanate of Oman

\section{EXISTING SYSTEM}

This website has a part for the photo gallery that is responsible for displaying the events, but it just displays pictures with the name of the place without any additional information. Events have a big role in a lot of institutions, but most people do not know of these events, and their significance.

The problem faced by people who want to attend the event and the person who wants to present the event. The persons who are not able to attend the events may not know about the place, time or aim of the event but with this application this will be easy for them. Also the person who wants to conduct an event will face some problems like there may not be a large number of attendees or because of lack of information and publicity

\section{PROPOSED SYSTEM}

Through this application users held can access all available events and find out about when and where events and other information they need to know about this event. This application will help the user to know about the events and facilitate ease of access to information, communication and participation. Organizers of the event are given a platform for the commercialization and deployment of their activities.

\section{LITERATURE REVIEW}

In the book on "project management" by the focus is on the tools and techniques of project management and how projects should evolve, identifying the true need of any project. Project Management includes a number of different processes, such as the planning process, the process of organization and resources to control the process in order to ensure the success of the project on time and at a lower cost with the required specifications and quality assurance of the project. There are some basic stages. The first stage is a primary stage and it this is the stage to determine the nature of the project. This stage is of important in the project. The second phase of the project is the stage of planning and designing by which the time as well as the expected cost. Of the project is determined the other stages are monitoring phase of the project and implementation of the project and these are the most important phases in the functioning of the project. (Heerkens, 2002), This book helps a lot to know about project management and it includes most of the information needed for planning.

In this book "Zen Cart" discusses the step by step to apply different templates, change the text, modify, and create new templates. He also explains some of the details about the use of creating a new language and also shows how we can program and use the application for development (Sarkar, 2008). Through the book, the project can be developed. It also provides skills to learn how to attract more customers through attractive design.

In this book "UML fundamentals" explains more information about UML. In addition this book shows some examples to understand how to draw use case diagram, class diagram and sequence diagram (Dr. Ernest, 2001). This book helps to draw all diagrams correctly.

"Feasibility study" is one of the important points in any project. In this book Feasibility Studies describes a feasibility study as study to achieve a general idea of the problem and to assess whether it has feasible solutions. Any system analyst has to work with representatives from the area to benefit from the solution. This book display more than one point for this topic, such as some secondary issues and why do so few new projects succeed (Rodney, 2007). This will help to do the project successfully without mistakes

In this book titled "Software Development Methodology" states that today a large group of technology has been developed over the past 50 years to make the programs much more reliable and trustworthy some software development needs change, so do the programs that are designed to satisfy those So new hardware technology enables and encourages new applications.(Edwards, 2002) Can be selected from this book the best methodology for the project.

\section{ARTICLE}

In the article "Event management: from the classroom to the real world", it is suggested that there is always a need for effective event management skills to achieve success in all aspects of business. Special event planning needs a lot of skills, including attention to detail, organization, and discipline and more patience. The goal of the author in teaching the course in event management is to provide a practical way to encourage a sense of civic responsibility and autonomy in each learner. A special occasion, is organ used in direct contact with the community the agency, promotes awareness of organ functions of the organization the objectives of the specific acts of charity (Hal. Walker, 1998). All this information helps to create more functions to create unique application. 
In this article about how to use the event management dimensions of effective strategies. They worked on the case for analyzing a sporting event based on events management and marketing perspectives study event. Data were collected in the study through primary as well as secondary data sources. The main data used was collected from interviews and observation. This study focuses on event management dimensions, transportation, human resources, budgeting and risk management (H.Kose, M.Argan, M.Argan, 2011). All these points can be included for new ideas and to achieve one of the objectives.

\section{WEBSITE}

This website will give a lot of idea about mobile development framework. It demonstrates the framework for mobile development (Altova.com).

"Online courses" is one of the best websites which displays more courses about programming. In this website are can write any course are wants to. It explains and is useful for anyone who wants to take courses online. This website will be used to get more information and ideas for this project (Udemy.com).

"The Events in Dubai" website is similar in design and develops an application for Oman Events.

"Events in Dubai" is one of the sites containing many beautiful events to enjoy and get useful information about each event. This site is an example of events where the user can search the events and famous places in Dubai. Through this site some styles can be created like this site, and this site helps me to make beautiful designs. This project is about development application but more ideas can be taken from this site, because it includes the same topics and goals. So it can be used to develop this project.

\section{Methodology}

The methodology is a set of stages that are applied and implemented to achieve the proposed project. Methodology selection depends on the project nature. There are several different methodologies which have different advantages and limitations. Compare and contest this section will the various methodologies and select the best one of them for implementation in this project.

\section{DSDM (DYNAMIC SYSTEM DEVELOPMENT METHOD)}

Dynamic System Development Method is a process that focuses on the achievement of all business solutions quickly and efficiently and it seven phases are as follows:

\section{Pre-Project:}

At this stage proposals are presented for the selection of the project.

\section{Feasibility Study:}

Definition the basic problem and assessment of expected costs.

\section{Business Study:}

In this phase is showing core business a study of all the work, such as the feasibility study.

\section{Functional Model Iteration:}

This phase focuses on aspects of the business.

\section{Design:}

At this stage, all associated design details and design of application are displayed.

\section{Implementation:}

It is the stage that is the transfer of development environment to execution environment.

7. Post-Project:
This stage includes evaluation of the performance of the application and addition of other improvements if necessary to do so.

\section{INTERVIEW}

Figure 3.4: Shows DSDM

I visited the Ministry of Information on 12 / October / 2016. I meet with person who works in the Ministry of Information, the purpose of this interview was discuss about my new idea and discuss about the website available to them and know the problems they faced. I asked some questions what I needed to know about the Ministry of Information.

\section{INTERVIEW}

I visited the Ministry of Information on 12 / October / 2016. I meet with person who works in the Ministry of Information, the purpose of this interview was discuss about my new idea and discuss about the website available to them and know the problems they faced. I asked some questions what I needed to know about the Ministry of Information.

\section{OBSERVATION}

12 / October / 2016 during my visit to the Ministry of Information I've noticed that the institution is working on media development and dissemination of information for important events in the Sultanate of Oman. The institution is working hard but nevertheless there different categories do not know about most of the events that occur in the Sultanate of Oman, so I decided to underline the importance of knowledge of the events and participate in them through the use of the new application.

\section{Flow Chart Diagram}

The flow chart is how the flow stages. The illustration below shows the status of the application when the administrator uses this application that you must enter a user name and password correct way and then the application will open and he could successfully complete the rest of the operations and then exit the application. In the case enter user name and password in the wrong way will not allow him to enter into the application.

\section{ER Diagrams}

Entity Relationship a diagram is explains and displays the items associated with each. Also represents the relations between people and places, and elements within this application. And help to define the important operations. It can be used to facilitate the construction of the database. 


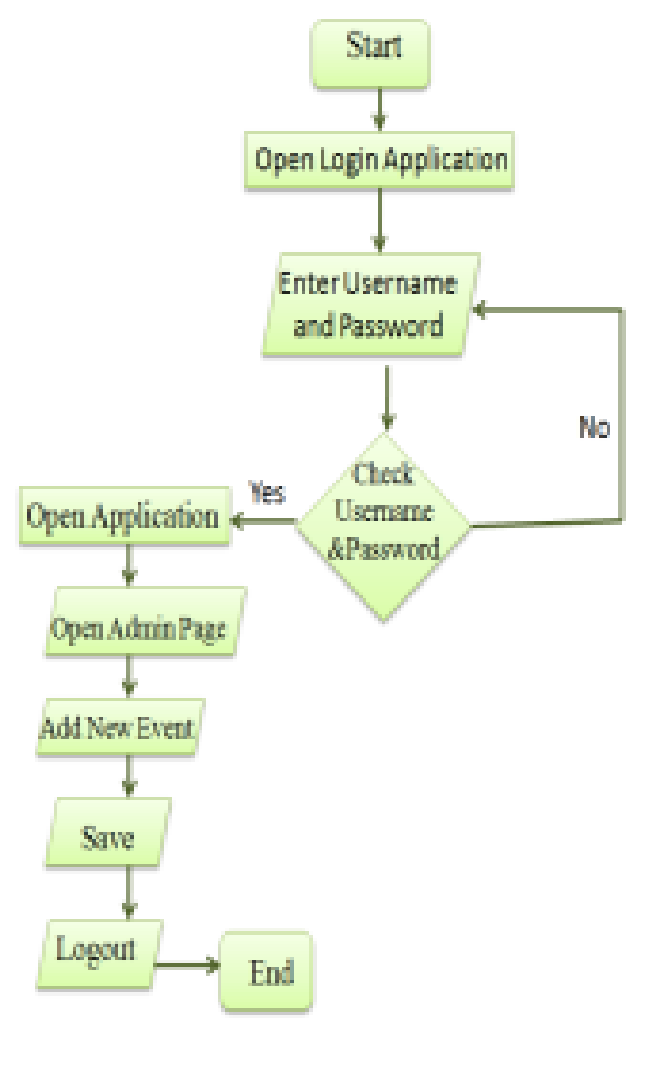

Figure: Shows Flow Chart Diagram

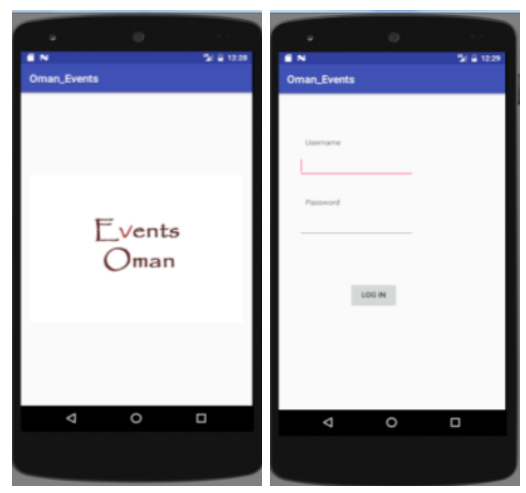

Conclusion

The project is development of a special application to events that occur in the Sultanate of Oman. The key reason for the selection of this project is to achieve an easy way for users who searching for events also to highlight the importance of the events. The application facilitates the user to search for details of any event in addition to know events carried out by the Sultanate of Oman through the reports presented by the application and assist the process of obtaining statics. In addition, all data will be stored in a security system to protect all data.

\section{References}

Sarkar, S. (2010).Zen Cart: E-commerce Application Development: A step-by-step developer's guide PDF Book. First ed. PACKT

Amazon.com (2012), Bookstore Example [online] available from< https://www.amazon.com/>

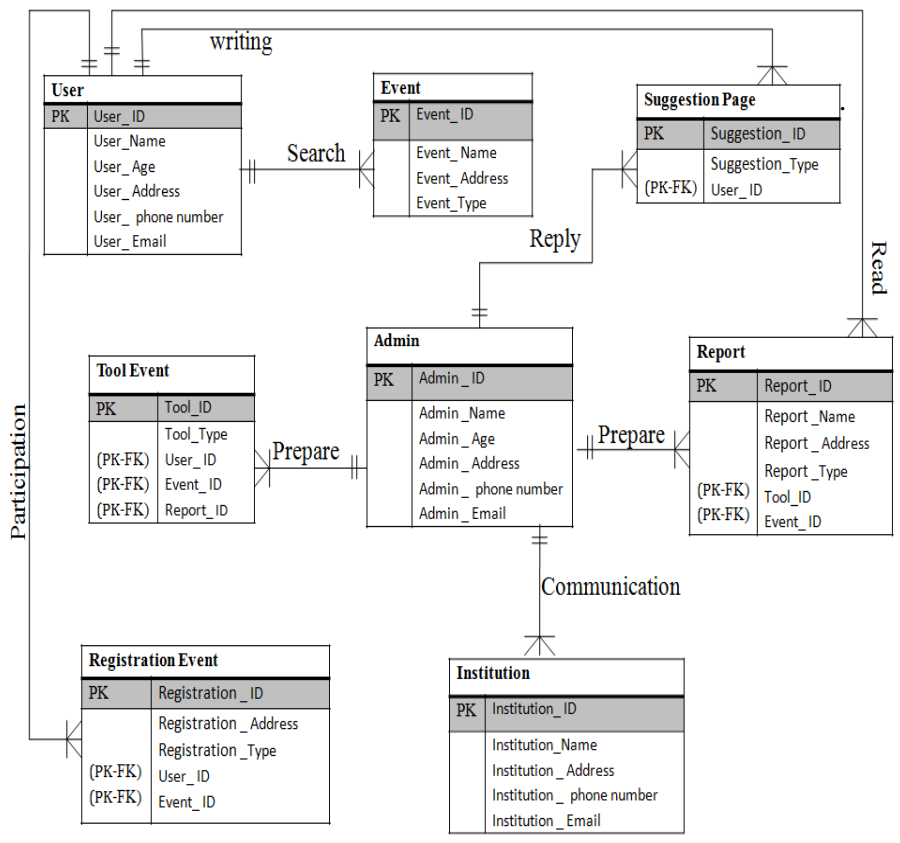

Edwards (2006), Software Development Methodology [online]available

from<https://www.google.com/search?q=Software+Dev elopment+Methodology\&oq=Software+Development+

Methodology\&aqs=chrome..69i57j015.1256j0j1\&sourcei

D $\mathrm{d}=$ chrome\&ie=UTF8UTF8\#q=book+Software+Develop

¿ ment+Methodology+Today > [15/November/2016]

Jeffrey, 2013.Data Analysis [online]. available from < http://www.businessdictionary.com/definition/dataanalysis.html > [20/November/2016]

About.com (2016). Entity Relationship Diagram [Online] available from< http://databases.about.com/cs/specificproducts/g/er.htm $>$ [25/November/2016]

Altova.com (2016). Entity Relationship Diagram [Online] available from< https://www.altova.com/umodel/use-case-diagrams.html $>$ [27/November/2016]

Figure: ER Diagram 